\title{
Factors influencing ERP implementation in Indian SMEs: An empirical analysis
}

\author{
Rana Basu $^{\mathrm{a}^{*}}$, Parijat Upadhyay ${ }^{\mathrm{b}}$ and Pranab k Dan ${ }^{\mathrm{a}}$
}

${ }^{a}$ Department of Industrial Engineering and Management, West Bengal University of Technology, BF-142, Sector - I, Salt Lake City, Kolkata PIN - 700064, India

${ }^{b}$ Globsyn Business School, XI 11 \& 12, Block EP, Sector-V, Salt Lake City, PIN - 700091, India

\begin{tabular}{|c|c|}
\hline$\overline{\text { ART I C LE I NFO }}$ & A B S TRACT \\
\hline $\begin{array}{l}\text { Article history: } \\
\text { Received October } 202010 \\
\text { Received in revised form } \\
\text { 25 December } 2010 \\
\text { Accepted } 6 \text { January } 2011 \\
\text { Available online } \\
8 \text { January } 2011 \\
\text { Keywords: } \\
\text { ERP implementation } \\
\text { SME } \\
\text { India } \\
\text { Factor analysis } \\
\text { MSME }\end{array}$ & $\begin{array}{l}\text { Enterprise Resource Planning (ERP) is essentially a commercial software package that enables } \\
\text { the integration of transaction - oriented data and business processes throughout an organization. } \\
\text { In order to remain competitive in this global business scenario, the small and medium scale } \\
\text { enterprises (SMEs) are opting for ERP implementation. In Indian SME sector, the adoption of } \\
\text { ERP is rapidly increasing. Literature shows many instances where organizations, even after } \\
\text { implementing such novel information systems like ERP, are unable to derive the benefits of } \\
\text { integration. It is, therefore, not surprising that implementation of enterprise information systems } \\
\text { in general is quite difficult due to their size, scope and complexity. Therefore, there is a need to } \\
\text { identify some issues that would lead to positive outcome for the implementation of ERP } \\
\text { systems in the context of Indian SME sector. This paper thus attempts to identify and to } \\
\text { prioritize the factors influencing proper implementation of ERP systems in a business } \\
\text { organization particularly for Indian small and medium businesses (SMBs). The research } \\
\text { presented here is specifically targeted the Indian SMEs, which have already completed the } \\
\text { process of implementing ERP system. }\end{array}$ \\
\hline
\end{tabular}

\section{Introduction}

Enterprise Resource Planning (ERP) systems have emerged as the centre of successful information management system and are considered as the backbone of organizations. Today, organizations of any magnitude have implemented or in the process of implementing ERP systems in order to remain competitive in this global business scenario. ERP can be regarded as highly integrated management information system having the capability to manage all aspects of business operations of organizations, which include production, manufacturing, sales, accounting, customer service, etc. ERP are increasingly becoming accepted platform for the small and medium scale industrial sectors and it is viewed as one of the ways to achieve competitive advantage and to reengineer business process (Gable \& Stewart, 1999). To achieve synergy across product lines, these businesses must implement a set of standard business applications and consistent data definitions across all business units. ERP packages are extremely useful for integrating a global company and for providing a 
"common language" throughout the organizations. Over the past few years, global economic downturn has put some spotlight on many business organizations of any magnitude. Indian small and medium business were also affected with such scenario. However, the large establishments have attempted to tackle in their own way and it is the small and the medium scale enterprises (SME) that are showing their huge potential growth.

Indian SMEs contribute well above $60 \%$ of country's gross domestic product (GDP) and, because of its potential growth ERP, vendors are moving their attention towards small and medium business (SMB) by offering customized and cheaper solutions from both the organizational and technological point of view (Chen, 2001). SME creates the largest employment opportunities for the Indian populace. India's SME sector is a vibrant, dynamic, flexible and productive entity, containing as many as 12 million units and employing around 30 million people. At the time of removal of quantitative restrictions under WTO in 2001, it was widely feared that the sector would collapse under the onslaught of global products. On the contrary, the sector quickly adapted and restructured itself to face the competition head-on. It embraced high technology, accepted norms of quality and competitiveness and continued to expand faster than the rest of the industrial economy.

A vast majority of small and medium scale organizations have some significant constraints in their resources. While Indian SMEs overlook the benefits of integrating ERP systems stating that such ERP software are beyond their budgets as the reason, but there is no doubt that the implementation of ERP software can improve the company's performance as well. The awareness of implementing enterprise business application (i.e. ERP) among SMEs is less than 35\%, as compared to over $80 \%$ for large organizations as per survey conducted by International Data Corporation (IDC). The critical influencing business drivers for SME segment will be to increase the overall business efficiency, to increase the capital and labor productivity and to reduce the fixed and variable cost. Research and survey by leading IT vendors clearly points out that the need for technology solutions is not only confined to Tier 1 cities in India but also business organizations operating from Tier II and Tier III cities also need ERP solutions as well. As all ERP vendors are focusing on this market, the Indian SME segment will have many alternatives to choose any one out of such high competitive price.

It has been found from the outcome of several researches that the implementation of ERP systems is more complex and expensive task for small organizations (Mabert et al, 2001; Koh \& Simpson, 2007). Literature shows many instances where companies, in spite of spending huge amount of money, are not able to derive any benefits out of it. A number of publications have highlighted the problems and frustrations that the companies had to go through while implementing such information system. A study by Aberdeen group finds SMEs are focusing on growth strategies and service to customers, sometimes balancing between the two, but more often, they are focusing exclusively on one or other. As organizations grow in their sizes and improve performance, they are more likely to invest in an ERP system that will grow with them. However, growth cannot come at the expense of customer service. So, Micro-small and medium scale enterprises (MSME) tend to operate in distributed environment and hence seek help from enterprise business applications (e.g. ERP in particular) in order to streamline and integrate business operations. As cases of ERP failures have increased, many studies try to identify the factors for Indian small and medium scale enterprises that could lead to successful implementation process of ERP. The research presented here is specifically targeted for Indian SMBs which have already completed the process of implementing ERP systems. The aim is to capture the experiences of the people involved in the process of implementation and to bring out the relevant factors.

\section{Literature Review}

The following summarizes the review literature of ERP implementation issues of SMEs in the context of developing countries. 
Nau and Lau (2001) identified certain factors by analyzing selective articles for successful implementation of ERP which are as: ERP team composition, support from top management, business plan and vision, proper communication, project management, business and legacy systems, $\mathrm{S} / \mathrm{W}$ development, testing and troubleshooting, effective decision making, effective training.

Muscatello (2002) surveyed the essential factors for the implementation of ERP: Business-oriented ERP strategy, leaders' support, complete ERP plans, clear and stable project range, restructuring business process before ERP taking effect, and training, proper ERP module, assessment of current sub-system and hardware facilities, definite project target, performance evaluation system, and Fulltime project manager. Organizations of any magnitude select a package that is user friendly having adequate scope for scalability and covering wide array of business processes.

The selections of ERP package always need to have proper and careful attention (Kraemmergaard \& Rose, 2002; Yusuf et al., 2004; Al-Mashari, 2003; Somers \& Nelson, 2001, 2004). Several researchers and practitioners analyzed and focused on the issues that contribute to successful implementation of ERP (Ewusi-Mensah, 1997; Stapleton \& Rezak, 2004; Weightman 2004; Anexinet, 2006; Kimberling, 2006; Ibrahim et al., 2008; Jafari et al., 2006). Those issues are: support from top management, proper education and training, proper project management, clear goals and objectives, project champion, change management.

Jafari et al. (2006) carried a research for Malaysian SMEs and identified ten important issues for the success of ERP implementation. These issues are commitment and support from higher management, proper and clearly defined goals and objectives, effective communication, proper project management, business process reengineering, data accuracy, suitability of hardware and software, vendor support, user education and training and involvement of user in the process. Woo (2007) carried out research for major Chinese organizations and reported six critical issues for the successful implementation of ERP systems which are: Management commitment and support, proper composition of project team, proper project management, business process change, effective education and training, proper and effective communication. Upadhyay and Dan (2008), carried out research study for Indian SME organizations where the researchers empirically assessed and, on the basis of responses received from the respondents, identified certain issues that actually would lead to the success of ERP implementation. The issues include properly defined goals and objectives, adequate user training and education, competency in project implementation team, acceptance of change brought about by implementation, proper assistance from vendor and role of external consultant.

Upadhyay and Dan (2009) performed a similar research for Indian SME's and revealed that certain critical factors could lead to positive implementation of ERP. The factors include top management support, proper goals and objectives, user knowledge, project champion, project team competency, improve work efficiency, scalability and scope and ERP importance. Noudoostbeni et al. (2009) assessed important success factors and failure factors in Malaysian SME companies and tried to recognize the most effective ones. From the research, the critical issues identified for successful implementation are proper team composition and effective training of users. In addition, two issues identified responsible for the failure of the implementation are poor project planning and inappropriate training method. Poonam Garg. (2010) identified and validated the critical success factors empirically for ensuring successful implementation of ERP packages in the context of retail industry in India. The identified top management commitment, product selection, project management, team composition and training and education as the most important issues.

\section{Research Objective and Methodology}

There are certain factors on the context of the implementation of ERP projects. This study attempts the critical success factors that the organizations must focus on to be successful. Identifying the 
critical success factors is important and need careful attention. The issues allow firms to decide whether they have the required capability to build the necessary requirements to meet them or not.

As we can observe from the previous literature survey, there are different issues for positive implementation of ERP. The content validity of these constructs was tentatively established by extensive review with top executives and other stakeholders. Some items were removed from the construct if their removal results in an increase in the reliability estimates. By reviewing the existing literature, we can identify 29 issues that lead to positive implementation of ERP in organizations. Those few were found inapplicable to the context of ERP implementation in SME's of India. Further investigations from the previous research and from the questionnaire survey revealed that 17 most important issues. The study of this paper also uses these factors for study of this paper and they are summarized in Table 1.

\section{Table 1}

The important factors influencing ERP implementation

\begin{tabular}{lll}
\hline Top Management Support & Scalability \& scope & Project sponsor \\
Properly defined goals \& objectives & ERP Importance & Package Selection \\
\cline { 2 - 2 } & Project Management & Vendor Support \\
Project Champion & User Training & Prevailing IT Infrastructure \\
Cost of Project & External Consultant & ERP Team Composition \\
Improve work efficiency & Interdepartmental Communication & \\
\hline
\end{tabular}

\subsection{Survey Methodology}

The researchers identified those Indian organizations which have recently gone through the implementation process of ERP system (any module, any vendor). All such organizations are SME in nature. Invitations to participate in the survey requested responses from the implementers of enterprise resource planning (ERP) systems and those who have already worked for Indian small and medium scale enterprises (SMEs). The survey uses five point Likert level scale for each 17 items where " 1 " means strongly disagree and " 5 " means strongly agree. These five item-scales were empirically tested and validated.

Questionnaire survey method was selected following the previous study to evaluate the importance of the success issues found from the review of literature. The researchers used postal survey questionnaire as the research instrument. The questionnaire is focused on the importance of success issues that clarified from the literature. It identifies the respondent's perception of the importance of the issues responsible for positive implementation of ERP systems. For each of these issues, a number of elements or statements were formulated through the definition and description of each one in the literature.

\subsection{Data collection procedures}

The target respondent in each organization was the chief information officer, IT managers, or any other person responsible for the implementation of ERP systems. Overall, 104 responses were obtained for analysis representing wide variety of industries.

\section{Data analysis and results}

In this research, the raw data was captured in a spread sheet software package. The spreadsheet was then converted into statistical software package (SPSS vs.17). We performed factor analysis on explanatory variables with the objective to determine the minimum number of factors that account for the maximum variance in data. Confirmatory factor analysis is used to test how well the data fit into the proposed measurement model (Hatcher, 1994). We applied principal component analysis (PCA) with Varimax rotation. PCA is used in order to reduce the number of variables (Jolliffe, 2002). PCA 
is a mathematical procedure that transforms a number of possibly correlated variables into a smaller number of uncorrelated variables. PCA gives loading for each combination of variables and loading factors. Higher loadings mark a higher correlation between variable and factor. Thus, the factor can be interpreted as underlying latent variables. In this study, we follow the Kaiser criterion (Kaiser, 1960), which suggests selection of those factors with Eigen values having values greater than 1. PCA is a procedure, which is widely accepted in various applications of information systems domain and also proved to be feasible in research method (Karimi et al., 1996; Chang \& King, 2005). Table 2 summarizes the proportion of each factors variance explained by the other factors.

Initial communalities are the estimates of the variance in each variable accounted for all components or factors. Extraction communalities are the estimates of the variance in each variable accounted for by the factors (or components) in the factor solution. Smaller values indicate those variables, which do not fit well with the factor solution, and we must eliminate them from the analysis.

\section{Table 2}

Communalities

\begin{tabular}{lll}
\hline Factors & Initial & Extraction \\
\hline Top Management Support & 1.000 & .758 \\
Goal \&amp; Objective & 1.000 & .880 \\
User Knowledge & 1.000 & .826 \\
Project Champion & 1.000 & .864 \\
Project Cost & 1.000 & .757 \\
Improve Work Efficiency & 1.000 & .708 \\
Scalability \&amp; Scope & 1.000 & .755 \\
ERP Importance & 1.000 & .796 \\
Project Management & 1.000 & .821 \\
User Training & 1.000 & .568 \\
External consultant & 1.000 & .626 \\
Interdepartmental Communication & 1.000 & .799 \\
Sponsor & 1.000 & .762 \\
Package Selection & 1.000 & .733 \\
Vendor Support & 1.000 & .736 \\
Prevailing IT Infrastructure & 1.000 & .694 \\
ERP Team composition & 1.000 & .801 \\
\hline
\end{tabular}

Extraction Method: Principal Component Analysis.

Table 3 presents the Eigen-values in decreasing order of magnitudes for all seventeen factors. Eigen value gives the ratio of variation in the data explained by each factor to the variation in the data explained by all the variables. In this study, we extracted 6 important factors as shown in Table 3 .

Table 4 summarizes the results of the implementation of orthogonal rotation called Varimax. Rotation is a method, which simplifies the interpretation of factor analysis. Varimax is one of the most popular orthogonal rotations, which aims to maximize the variance of squared loadings on a factor to produce some high and low loadings for each factor (Kim \& Mueller, 1978). Here the factors are rotated among each other so that they are mutually orthogonal i.e. perpendicular in $n$ dimensional plane. 


\section{Table 3}

Total Variance Explained

\begin{tabular}{|c|c|c|c|c|c|c|c|c|c|}
\hline \multirow[t]{2}{*}{ Component } & \multicolumn{3}{|c|}{ Initial Eigen Values } & \multicolumn{3}{|c|}{$\begin{array}{l}\text { Extraction sums of squared } \\
\text { loadings }\end{array}$} & \multicolumn{3}{|c|}{$\begin{array}{c}\text { Rotation sums of squared } \\
\text { loadings }\end{array}$} \\
\hline & Total & $\begin{array}{c}\% \text { of } \\
\text { variance }\end{array}$ & $\begin{array}{c}\text { Cumulative } \\
\%\end{array}$ & Total & $\begin{array}{c}\% \text { of } \\
\text { variance }\end{array}$ & $\begin{array}{c}\text { Cumulative } \\
\%\end{array}$ & Total & $\begin{array}{c}\% \text { of } \\
\text { variance }\end{array}$ & $\begin{array}{c}\text { Cumulative } \\
\%\end{array}$ \\
\hline 1 & 3.991 & 23.475 & 23.475 & 3.991 & 23.475 & 23.475 & 2.995 & 17.619 & 17.619 \\
\hline 2 & 2.527 & 14.866 & 38.341 & 2.527 & 14.866 & 38.341 & 2.541 & 14.948 & 32.567 \\
\hline 3 & 2.092 & 12.305 & 50.645 & 2.092 & 12.305 & 50.645 & 2.157 & 12.688 & 45.255 \\
\hline 4 & 1.749 & 10.290 & 60.935 & 1.749 & 10.290 & 60.935 & 1.970 & 11.586 & 56.842 \\
\hline 5 & 1.398 & 8.221 & 69.156 & 1.398 & 8.221 & 69.156 & 1.827 & 10.748 & 67.590 \\
\hline 6 & 1.124 & 6.615 & 75.771 & 1.124 & 6.615 & 75.771 & 1.391 & 8.182 & 75.771 \\
\hline 7 & .824 & 4.848 & 80.619 & & & & & & \\
\hline 8 & .713 & 4.193 & 84.813 & & & & & & \\
\hline 9 & .572 & 3.366 & 88.179 & & & & & & \\
\hline 10 & .523 & 3.076 & 91.255 & & & & & & \\
\hline 11 & .415 & 2.441 & 93.696 & & & & & & \\
\hline 12 & .326 & 1.918 & 95.614 & & & & & & \\
\hline 13 & .271 & 1.593 & 97.207 & & & & & & \\
\hline 14 & .236 & 1.391 & 98.598 & & & & & & \\
\hline 15 & .112 & .658 & 99.256 & & & & & & \\
\hline 16 & .083 & .489 & 99.745 & & & & & & \\
\hline 17 & .043 & .255 & 100.000 & & & & & & \\
\hline
\end{tabular}

The rotation minimizes the number of variables having higher correlations on a factor. Since the rotation is orthogonal, the resulting factors will be uncorrelated. We normally choose the factors whose Eigen values are more than one. In the rotated factor, the variables with higher loading factor are considered more important. Thus, according to the results of Table 3, six factors are chosen as the most influencing items for ERP implementation including User knowledge, ERP importance, Interdepartmental communication, Package selection, ERP Team composition, Project champion. Fig. 1 shows the results of the analysis performed by SPSS vs. 17 software package.

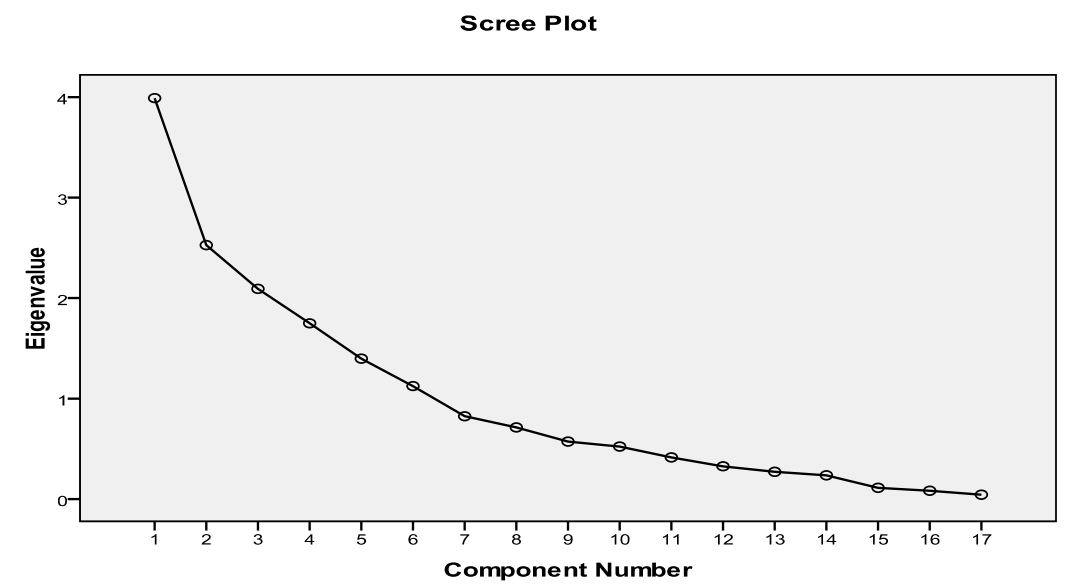

Fig. 1. The results of Eigen values for 17 factors 
Table 4

Rotated Component Matrix

\begin{tabular}{lcccccc}
\hline Factors & \multicolumn{7}{c}{ Component } \\
& 1 & 2 & 3 & 4 & 5 & 6 \\
\hline Top Management Support & .287 & .054 & .664 & .233 & .327 & .267 \\
Goal \&amp; Objective & .856 & -.041 & .223 & .183 & -.232 & -.088 \\
\hline User Knowledge & .875 & -.056 & -.073 & .219 & .035 & -.039 \\
\hline Project Champion & .003 & .040 & .134 & -.090 & -.130 & .905 \\
Project Cost & -.434 & .641 & -.295 & .248 & .078 & -.061 \\
\hline Improve Work Efficiency & .467 & .597 & .218 & .134 & -.109 & -.236 \\
\hline Scalability \&amp; Scope & .115 & .011 & .788 & -.270 & -.124 & -.180 \\
\hline ERP Importance & .120 & .863 & -.027 & -.046 & .116 & .142 \\
Project Management & .720 & .414 & .157 & -.260 & -.040 & .194 \\
\hline User Training & .554 & .166 & .183 & .099 & .030 & .434 \\
External consultant & -.121 & -.202 & .269 & .028 & .705 & -.029 \\
\hline Interdepartmental Communication & .046 & -.063 & .832 & .085 & .046 & .301 \\
Sponsor & .037 & .843 & .016 & .005 & -.218 & .047 \\
\hline Package Selection & .277 & .198 & .037 & .779 & -.095 & -.003 \\
\hline Vendor Support & .168 & -.012 & .068 & .730 & -.372 & -.174 \\
\hline Prevailing IT Infrastructure & -.177 & -.130 & -.207 & .640 & .426 & .110 \\
\hline ERP Team composition & .001 & .094 & -.122 & -.191 & .851 & -.127 \\
\hline
\end{tabular}

Extraction Method: Principal Component Analysis, Rotation Method: Varimax with Kaiser Normalization

Reliability analysis: In order to examine the reliability of the data we calculated Cronbach alpha. In our study, Cronbach's alpha was calculated as 0.681, which is well above the minimum required level suggested by Hair et al. (1998), and this validates the reliability of our study.

Results: Component 1 represents Proper knowledge and experience of user in implementation, Component 2 represents ERP importance, Component 3 represents Proper and effective interdepartmental communication, Component 4 represents Proper selection of package, Component 5 represents ERP Team composition, and Component 6 represents Project champion. Table 5 summarizes the results of the ranked factors which influence ERP implementation, significantly.

\section{Table 5}

The priorities of six most influencing factors

\begin{tabular}{lcc}
\hline Factors (Components) & Factor Loadings & Priority/Rank \\
\hline User Knowledge & .875 & 2 \\
ERP importance & .863 & 3 \\
Interdepartmental communication & .832 & 5 \\
Package selection & .779 & 6 \\
ERP Team composition & .851 & 4 \\
Project champion & .905 & 1 \\
\hline
\end{tabular}

\section{Discussion}

The following presents a brief discussion on the prioritized factors in descending order.

\subsection{Project Champion}

The role of project champion is critical to derive consensus and oversee for the entire life cycle of the implementation. The need to have project champion is a crucial factor for organizations of any 
magnitude who wish to implement ERP system, successfully. The project champion is the one who must have the power to set goals and to introduce legitimate changes. Project Champion must have the proper leadership quality (Mandal \& Gunasekaran, 2003) and technical and managerial skills (Kraemmergaard \& Rose, 2002).

\subsection{User Knowledge}

The proper skills and knowledge are expected from the ERP users in an organization for successful implementation process. The users must possess the advanced IT skills and knowledge.

\subsection{ERP Importance}

As per International Data Corporation (IDC), there is a good awareness of ERP system in large organization sector but there are some smaller scale businesses and even medium scale enterprises (MSME) which are also adopting ERP applications. According to the survey of IDC, the awareness and importance of implementation of ERP in Indian SME's is less than 35\% as compared to more than $80 \%$ for large organizations. The benefits that the organizations are enjoying after successful implementation of ERP systems must be taken into consideration in order to elevate the importance of this integrated package (i.e. ERP).

\subsection{ERP Team composition}

The composition of the ERP project team refers to the proper selection of the team members who would be driving the ERP implementation. It has also been mentioned frequently in the literature that there is a major need to put in place a solid, core implementation team comprised of organizations people with good skills. Nah et al. (2003) also cited the need for the team to possess the necessary skills to execute when conducting the planning phase of the implementation. Indian SME's tend to suffer because of dearth of skilled personnel toward information systems operation.

\subsection{Interdepartmental Communication}

Al-Mashari (2002), asserted that among other reasons that may affect the success of ERP implementation in organizations of any magnitude, either positively or negatively is the capability to manage the complexity of information flow. Organizations must have a detailed communication plan and strategy which lead to positive outcome of the implementation process. Effective interdepartmental communication is the one that makes everything run smoothly (Schwalbe, 2000). It is much more crucial for organizations to control this or else will lead to coordination problems (Horgan, 1997), and may lead to serious disruption in the implementation of ERP systems. It has also been observed that from the Indian context, this issue poses serious problem, as the branch offices are located in different regions of the country, where language of communication is different.

\subsection{Package Selection}

Proper selection of package is a crucial aspect that would lead to successful implementation of ERP systems in organizations of any size. As far as the Indian SME is concerned, organizations select the package, which is more users friendly and specifically addresses the business process requirements. Thus, the selection of proper ERP package must be considered, significantly (Yusuf et al., 2004; AlMashari et al., 2003; Somers and Nelson, 2001, 2004).

\section{Conclusion}

The interesting aspect of the present research is the focus on Indian small and medium scale enterprises with the objective of identifying positive factors in implementing the ERP packages for Indian organizations. This research provided a partial support to explain the reasons for the success in implementing ERP projects for Indian SMEs as well as MSMEs as reported by various researchers. 
The investment in enterprise business applications remains the top priority for information technology (IT) specially when the organizations need to meet regulatory compliance. Companies spend around 20\% - 35\% of their implementation costs every year in maintaining the system. The findings are important for any organization in small and medium scale sector for leveraging the benefits of ERP systems. This research study attempted to highlight the important issues while implementing the ERP system in organization in order to run smoothly and successfully. It is evident from the published literature as well as from the researchers' point of view that organizations even after spending huge amount of costs in implementing the ERP applications are unable to derive the true benefits of such integration. Based on the responses received from the respondents, we found six major factors for ensuring successful implementation of ERP. The researchers in this study believe that the outcome of the results would help the managers and other people who are directly involve in the implementation process. Even the ERP vendors can take input from this study in their implementation approach while targeting SME's.

Beyond the presented results, there may be other factors that need to be explored. In the present economic situation, other issues that can have significant impact on the decision of SME's regarding the purchase and the implementation of an appropriate and suitable ERP package must be explored. Further to this, there is also a scope to enhance this study by taking different organizations into account and by increasing the number of respondents.

\section{References}

Al-Mashari, M. (2002). Enterprise resource planning (ERP) systems: a research agenda. Industrial Management \& Data Systems, 102, 165-170.

Al-Mashari, M., Al-Mudimigh, A. \& Zairi, M., (2003). Enterprise resource planning: a taxonomy of critical factors. European Journal of Operational Research, 146, 352-364.

Anexinet, R. B., (2006). Top 10 ERP implementation pitfalls Retrieved 11th February, 2010, from http://www.anexinet.com/pdfs/ERP_top10pitfalls3-2006.pdf

Chang, J.C.-J., \& W. King (2005). Measuring the Performance of Information Systems: A Functional Scorecard. Journal of Management Information Systems, 22 (1), 85-115.

Chen, I. J. (2001). Planning for ERP systems: analysis and future trends. Business Process Management Journal, 7(5), 374-386.

Ewusi-Mensah, K. (1997). Critical issues in abandoned information systems development projects. Communications of the ACM, 40(9), 74-80.

Gable, G. \& Stewart, G. (1999), SAP R/3 implementation issues for small to medium enterprises. Proceedings of the 5th Americas Conference on Information Systems, Milwaukee, WI, 779-81.

Garg, P. (2010). Critical success factors for enterprise resource planning implementation in Indian retail industry: An exploratory study. International Journal of Computer Science and Information Security, 8(2), 358-363.

Hair, J., Black, W., Babin, B., Anderson, R., \& Tatham, R. (1998). Multivariate Data Analysis, $6^{\text {th }}$ ed., New Jersey: Pearson Prentice Hall.

Horgan, T. (1997). Where to begin, CIO Web Business Magazine, October 1.

Hatcher, L. (1994). A step-by-step approach to using the SAS system for factor analysis and structural equation modeling . Cary, NC: SAS Institute.

Ibrahim, A. M. S., Sharp, J. M., \& Syntetos, A. A. (2008). A framework for the implementation of ERP to improve business performance: A case study. In Z. Irani,S. Sahraoui, A. Ghoneim, J. Sharp, S. Ozkan, M. Ali \& S. Alshawi (Eds.), Proceedings of the European and Mediterranean Conference on Information Systems (EMCIS)

Jafari, S. M., Osman, M. R., Yusuf, R. M., \& Tang, S. H., (2006). ERP systems implementation in Malaysia: The importance of critical success factors. Engineering and Technology, 3, 125-131.

Jolliffe, I.T. (2002). Principle Component Analysis. $2^{\text {nd }}$ edition, Springer, New York, USA. 
Kaiser, H.F. (1960). The Application of Electronic Computers to Factor Analysis. Educational and Psychological Measurement, 10 (1), 141-151.

Karimi, J., Y Gupta, \& T. Somers (1996). Impact of Competitive Strategy and Information Technology Maturity on Firms' Strategic Response to Globalization. Journal of Management Information Systems, 12 (4), 55-88.

Kim, J.-O., \& Mueller, C.W. (1978). Factor analysis: Statistical methods and practical issues. Beverly Hills, CA: Sage.

Kimberling, E., (2006). 7 critical success factors to make your ERP or IT project successful Retrieved 11th February, 2010, from http://it.toolbox.com/blogs/erp-roi/7-criticalsuccess-factors-to-makeyour-erp-or-it-project-successful-12058

Koh, L. S. C., \& Simpson, M. (2007). Could enterprise resource planning create a competitive advantage for small businesses? Benchmarking: An International Journal, 14(1), 59-76.

Kraemmergaard, P. and Rose, J., (2002). Managerial competences for ERP journeys. Information Systems Frontiers, 2(4), 199-212.

Mabert, V.A., Soni, A., \& Venkataramanan, M.A. (2001), Enterprise resource planning: common myths versus evolving reality. Business Horizons, 44(3), 69-76.

Mandal, P., \& Gunasekaran, A. (2003). Issues in implementing ERP: a case study. European Journal of Operational Research, 146, 274-83.

Muscatello, J. R. (2002). An Exploratory Study of the Implementation of Enterprise Resource Planning (ERP). Dissertation, Cleveland State University.

Nah, F. F., \& Lau, J. L., (2001). Critical factors for successful implementation of enterprise systems. Business Process Management, 7(3), 285- 296.

Nah, F., Zuckweiler, K., \& Lau, J. (2003). ERP Implementation: Chief Information Officers' Perceptions of Critical Success Factors. International Journal of Human-Computer Interactions, 16(1), 5-22.

Noudoostbeni, A., Yasin, N. M., \& Salarzadeh, H. (2009). To investigate the success and failure factors of ERP implementation within Malaysian Small and Medium Enterprises (SMEs). The International Conference on Information Management and Engineering (ICIME), 157-161. Kuala Lumpur, Malaysia: IEEE.

Schwalbe, K. (2000), Information Technology Project Management, Course Technology, Cambridge, MA.

Somers, T.M., \& Nelson, K., (2001). The impact of critical success factors across the stages of enterprise resource planning implementations, Proceeding of the 34th Hawaii International Conference on System Sciences, Hawaii.

Somers, T.M., \& Nelson, K.G. (2004). A taxonomy of players and activities across the project life cycle, Information \& Management, 41, 257-78.

Stapleton, G. \& Rezak, C. J., (2004). Change management underpins a successful ERP implementation at Marathon Oil. Journal of Organization Excellence, 23(4), 15-21.

Upadhyay, P. \& Dan, P.K. (2008). An explorative study to identify the Critical Success Factors for ERP implementation in Indian small and medium scale enterprises, IEEE, 295-299.

Upadhyay, P., \& Dan , P.K. (2009). ERP in Indian SME's: A Post Implementation Study of the Underlying Critical Success Factors, International Journal of Management Innovation System, $1(2), 1-10$.

Weightman, C. (2004). The top 10 ERP mistakes. Business Management (February), 36-40.

Woo, H. S., (2007). Critical success factors for implementing ERP: the case of a Chinese electronics manufacturer. Journal of Manufacturing Technology Management, 18(4), 431 -442

Yusuf, Y., Gunasekaran, A. \& Absthorpe, M. S. (2004). Enterprise information systems project implementation: a case study of ERP in Rolls-Royce. Journal of Production Economics, 87, 251266. 